\title{
Clinical experience with BIAsp 30: Results from the Bangladesh cohort of the global $A_{1}$ chieve study
}

\author{
Latif $\mathrm{ZA}^{1}$, Pathan $\mathrm{MF}^{1}$, Mannan $\mathrm{MA}^{2}$, Siddiqui $\mathrm{MNI}^{3}$, Ashrafuzzaman $\mathrm{SM}^{1}$, \\ Rahman $\mathrm{MM}^{4}$, Sobhan $\mathrm{MJ}^{4}$ \\ ${ }^{1}$ Department of Endocrinology, BIRDEM Hospital, Dhaka, ${ }^{2}$ Department of Endocrinology, Dhaka Medical \\ College \& Hospital (DMCH), Dhaka, ${ }^{3}$ Department of Endocrinology, Mymensingh Medical College \& \\ Hospital (MMCH), Mymensingh, ${ }^{4}$ Medical Services, Novo Nordisk Pharma (Pvt.) Ltd., Bangladesh. \\ Email:zafaralatif2011@yahoo.com
}

\begin{abstract}
The aim of $A_{1}$ chieve was to remedy the deficit of data on the efficacy and safety of insulin analogues in routine clinical care in less well-resourced developed countries. To present results from the Bangladesh cohort of the $\mathrm{A}_{1}$ chieve study receiving BIAsp $30 \pm$ oral anti diabetic drugs. $\mathrm{A}_{1}$ chieve was a 6-month, observational study of 66,726 people with type 2 diabetes, started on insulin detemir, insulin aspart or biphasic insulin aspart (BIAsp 30) in 28 countries across four continents. A total of 1,093 subjects were recruited from 49 sites in Bangladesh and 580 subjects initiated on BIAsp 30 were studied. In the entire cohort, treatment with BIAsp 30 for 24 weeks significantly reduced mean $\mathrm{HbA}_{1 \mathrm{c}}$ $(2.8 \%, \mathrm{p}<0.001)$, fasting plasma glucose $(4.0 \mathrm{mmol} / \mathrm{L}, \mathrm{p}<0.001)$ and post prandial plasma glucose $(6.6 \mathrm{mmol} / \mathrm{L}, \mathrm{p}<0.001)$ levels from baseline. The rate of overall hypoglycaemic events in the entire cohort also reduced significantly at 24 weeks $(1.86$ to 0.02 events/person year, $\mathrm{p}<0.0001)$. BIAsp 30 can be considered as a safe and effective option for initiating as well as intensifying insulin therapy for type 2 diabetes.
\end{abstract}

\section{Introduction}

Current evidence-based guidelines from the International Diabetes Federation (IDF) suggest that insulin should be introduced when $\mathrm{HbA}_{1 \mathrm{c}}$ value of $\leq 7.5 \%$ are not achieved by means of lifestyle modifications and with the use of two to three oral glucose lowering drugs (OGLDs) ${ }^{1-3}$. It has also been well established that good glycaemic control can reduce the risk of microvascular complications in patients with $\mathrm{T}_{2} \mathrm{DM}^{4}$.

Although postprandial glucose excursion is a wellrecognized contributor to daytime hyperglycaemia, past therapies for diabetes have been based primarily on fasting glucose measures. However, basal control alone does not provide complete coverage, particularly for mealtime glycaemic excursions. Earlier studies suggest that morbidity and mortality associated with hyperglycaemia can be reduced by controlling the postprandial plasma glucose $(\mathrm{PPPG})^{\mathbf{5}, \mathbf{6}}$. Results from the DECODE (Diabetes Epidemiology: Collaborative Analysis of Diagnostic Criteria in Europe) study which was carried out in more than 25,000 subjects (including 1275 previously diagnosed with diabetes), showed that any increase in PPPG levels led to significant increase in mortality regardless of the fasting plasma glucose (FPG) levels ${ }^{5}$. The incidence of myocardial infarction was $40 \%$ higher in patients with PPPG greater than $10 \mathrm{mmol} / \mathrm{L}^{f}$. The importance of post prandial glucose (PPG) was reinforced by a study showing that glucose excursion after breakfast was a major contributor to failed glycaemic control in T2DM patients who were on OGLDs ${ }^{8}$.

Optimal glycaemic control can only be achieved through basal and post prandial coverage. Basal insulin addresses the issue of FPG alone but may not be a treatment option in post prandial hyperglycaemia. The premixed insulin analogue, biphasic insulin aspart 30 (BIAsp 30), consists of a rapid-acting soluble insulin (30\%) which effectively controls PPG and a long-acting protaminated insulin $(70 \%)$ which controls basal glucose between meals. For patients failing to maintain glycemic control on OGLD therapy, BIAsp 30 represents a convenient and simple option for initiating insulin treatment, as it can be injected once-daily (OD) in combination with OGLDs ${ }^{9}$.

Premixed insulin analogues are also ideal for patients opting for simple and convenient insulin regimen, having persistent post prandial 
hyperglycaemia despite receiving basal insulin and who are unwilling to mix different insulin formulations ${ }^{\mathbf{1 0}}$ and it can be up titrated to twice and even thrice daily, thus making intensification easier ${ }^{4}$.

The recent joint consensus guidelines from European Association for the Study of Diabetes (EASD) and American Diabetes Association (ADA) suggest basal insulin as the optimal initial regimen which can be up-titrated to basal-bolus or twice daily pre-mixed insulin regimen in patients having high $\mathrm{HbA}_{1 \mathrm{c}}$ levels $(\geq 9.0 \% \quad[\geq 75$ $\mathrm{mmol} / \mathrm{mol}])^{11}$.

Previous studies in Bangladesh showed that, achievement of $\mathrm{HbA}_{1 \mathrm{c}}$ target of the diabetic population on other drugs (OAD and human insulin) was only $22 \%$ in real life situation (Ref.: DiabCare Asia 2008).

$\mathrm{A}_{1}$ chieve is an observational study, designed to assess the safety and effectiveness of insulin analogues in real life setting of large diabetic populations (more than 65,000 patients comprising of insulin naive patients and prior insulin users from 28 countries) ${ }^{\mathbf{1 2}}$. The objective of the present study was to analyse the safety and efficacy of BIAsp 30 in people of Bangladesh.

\section{Materials and Methods}

Study design: As previous studies indicate that majority of people did not achieve good glycaemic status in real life situation with human insulin and or $\mathrm{OAD}$, the present study was designed to see efficacy and safety of analogue insulin.

This was a 24-week, international, prospective, multicentre, non-interventional, observational study of people with T2D who had begun using basal insulin detemir (Levemir, Novo Nordisk, Denmark), bolus insulin aspart (NovoRapid, Novo Nordisk) and biphasic insulin aspart 30 (NovoMix 30, Novo Nordisk), alone or in combination, to evaluate their clinical safety and effectiveness in routine clinical use outside the Western economies. The study was carried out in 3166 centres in 28 countries across Asia, Africa, Latin America and Europe, grouped into seven geographical regions: China; South Asia (Bangladesh, India, Pakistan); East Asia (Indonesia, Korea, Malaysia, Philippines, Singapore, Taiwan); north Africa (Algeria, Morocco, Tunisia, Libya); Middle East/Gulf (Egypt, Iran, Jordan, Turkey, Bahrain, Kuwait, Oman, Qatar, Saudi Arabia, UAE, Yemen); Latin America (Argentina, Mexico) and Russia. Participants were recruited between January 2009 and June 2010. The insulin therapies were prescribed by a physician in the course of normal clinical practice, were commercially avail-able and were funded according to local practice in normal routine care. Thus, the participant and advising physician determined the choice of insulin, the starting dose, administration frequency and any later changes to either dose or frequency. In the study, insulin analogues were used in accordance with the licensed approval from the local regulatory authority. Changes to OGLDs at the time of starting the insulin analogue, or thereafter, were entirely at the discretion of the participant and advising physician. There were no defined study-related procedures; measurements were made by the treating physician team only as determined by normal clinical care. Thus, safety and effectiveness of therapy were determined from measurements made at usual clinic visits. Trial visits were defined as baseline, interim (around 12 weeks from baseline) and final (around 24 weeks from baseline) visit. Data were collected from the physicians' clinical notes, and participants' recall and selfmonitoring diary/meter at each visit, as available. This information was transferred to a standard case report form (CRF).

Participants: A total of 66,726 people were included in the study. Any current and prior medications were acceptable for participant inclusion other than the insulin analogues being evaluated. Women who were pregnant, breastfeeding or had the intention of becoming pregnant were excluded. Ethics committee approval was obtained for each country, and signed informed consent from all participants. Participants were free to withdraw at will at any time. If they withdrew, the data collected were used for analysis until the point when consent was withdrawn. Safety events were reported according to the protocol. All investigators underwent specific training on the study protocol, CRF completion, informed consent and safety reporting procedures.

Assessments and outcome measures: The primary objective of this study was to evaluate the clinical safety of the insulin analogues by the incidence of serious adverse drug reactions (SADRs), including major hypoglycaemic events, considered related to the study insulin between baseline and final visit. Secondary safety assessments were the change in number of hypoglycaemic events in the last 4 weeks before interim and final visits, compared with the last 4 weeks before baseline visit, the change in number of nocturnal hypoglycaemic events during these periods and the number of adverse drug reactions (ADRs) from baseline to final visit. Major hypoglycaemic events were defined as events with severe central nervous system symptoms, consistent with hypoglycaemia, 
for which the person was unable to self-treat, and accompanied by plasma glucose $<3.1 \mathrm{mmol} / \mathrm{L}$ or 56 $\mathrm{mg} / \mathrm{dL}$, or reversal of symptoms after either food intake or glucagon or intravenous glucose administration. Minor hypo-glycaemia was any event, with or without symptoms of hypoglycaemia, with a plasma glucose reading below $3.1 \mathrm{mmol} / \mathrm{L}$ or $56 \mathrm{mg} / \mathrm{dL}$ that the participant was able to self-treat. Nocturnal hypoglycaemia was defined as a symptomatic event consistent with hypoglycaemia that occurred during sleep between bedtime after the evening insulin injection and before getting up in the morning. Efficacy assessments were change in $\mathrm{HbA} 1 \mathrm{c}$, fasting plasma glucose (FPG), postprandial plasma glucose (PPPG) and body weight between baseline and interim and final visits, and change in systolic blood pressure (SBP) and lipid profile at final visit. All laboratory measurements were made in local laboratories and were thus subject to local standardisation and quality control procedures. Quality-of-life assessments were made at baseline and final visit, and are communicated in a separate report. The rationale for choosing each study insulin regimen was recorded, with the aim of determining which factors influence the selection criteria of the specific regimen.

Statistical methods: Analyses were performed for the entire cohort (all participants), for the entire cohort divided as prior insulin-treated or insulinnaive, for the insulin analogue regimen used and by geographical regions (as above). As this was not a randomised trial, and as the characteristics determining choice of insulin regimen, time of starting insulin and concomitant medical conditions were not fully known, comparison between regimens, prior insulin use or not and regions is reported as a matter of observation only. The insulin regimens were defined as biphasic insulin aspart (premix) alone, insulin detemir alone, insulin aspart alone or insulin aspart with a basal insulin (this could include insulin detemir), or other. In each instance, the use or non-use of concurrent OGLDs was allowed. The sample size was based on the number of people $(20,000)$ exposed for 6 months required to confirm at $95 \%$ confidence a frequency of any one ADR of 15 events/100,000 person-years. This rate, for example, would detect a rate of major hypoglycaemia as reported in any published clinical trial. Analysis of all variables, including safety and efficacy outcomes, was performed using any participant entered into the study who had the data relevant to that analysis. Continuous variables were summarised using descriptive statistics and discrete variables were summarised using frequency tables (n, \%). All statistical analyses were two-sided, using a pre- specified 5\% significance level, unless otherwise stated. For hypoglycaemia change from baseline, the percentage of people reporting at least one event was analysed using Fisher's exact test. Prevalence data rather than incidence rate were tested as low event rates, in the circumstances where some people had recurrent events, could not be modelled in a statistically sensitive way. Change from baseline HbA1c, FPG, PPPG and blood lipids was analysed using an analysis of covariance (ANCOVA) model with baseline characteristics as covariates. The percentage of patients having $\mathrm{HbA} 1 \mathrm{c}<7.0 \%$ at 24 weeks was analysed using a logistic regression model using the factors and covariates of treatment, country, region, age, gender, ethnicity, body mass index (BMI), duration of diabetes, smoking status, total blood cholesterol, high-density lipoprotein (HDL) cholesterol, SBP and pre-study glucose-lowering therapy. Corresponding base-line HbA1c was included as a fixed effect. All data were analysed by Novo Nordisk using SAS (Version 9.1.3).

\section{Results}

A total of 580 patients from Bangladesh, participated in the study, were switched to premixed insulin analogue. The participant characteristics for the entire cohort divided as insulin-naive and prior insulin users are shown in the Table I. Patients in the prior insulin user group had longer duration of diabetes than the insulinnaive group (7.9 yrs vs. $6.3 \mathrm{yrs}$ ), had a higher BMI $\left(26.7 \mathrm{~kg} / \mathrm{m}^{2}\right.$ vs. $\left.25.2 \mathrm{~kg} / \mathrm{m}^{2}\right)$ and increased body weight (67.8 kgs vs $64.7 \mathrm{kgs})$. However, baseline $\mathrm{HbA}_{1 \mathrm{c}}$ was similar in both the groups $(10.0 \%$ in both). Also, the age was almost similar in prior insulin users and insulin naive groups.

Table I. Baseline characteristics of the Bangladesh cohort

\begin{tabular}{llcl}
\hline & $\begin{array}{l}\text { Entire } \\
\text { cohort }\end{array}$ & $\begin{array}{l}\text { Insulin } \\
\text { naive }\end{array}$ & $\begin{array}{l}\text { Prior insulin } \\
\text { users }\end{array}$ \\
\hline $\mathrm{N}(\%)$ & $580(100 \%)$ & $400(69 \%)$ & $180(31 \%)$ \\
$\mathrm{Sex}, \mathrm{M} / \mathrm{F}^{\hat{A}} \mathrm{~N}(\%)$ & $310(53.4) /$ & $220(55.0) / 90(50.0) /$ \\
Age $(\mathrm{yrs})$ & $270(46.6)$ & $180(45.0)$ & $90(50.0)$ \\
Duration of diabetes(yrs) & $6.8(5.5)$ & $6.3(5.4)$ & $7.9(5.5)$ \\
Bodyweight $(\mathrm{kgs})_{\mathrm{BMI}^{\S}\left(\mathrm{kg} / \mathrm{m}^{2}\right)}^{65.7(9.7)}$ & $64.7(9.3)$ & $67.8(10.4)$ \\
$\mathrm{HbA}_{1 \mathrm{c}}(\%)$ & $25.7(3.7)$ & $25.2(3.5)$ & $26.7(4.0)$ \\
\hline
\end{tabular}

$\hat{A}$ - malelfemale; $\$$ - body mass index; Data expressed in Mean (Standard deviation) for all variables except $N$ and $S e x$

Insulin dose and Blood glucose values: Treatment with BIAsp 30 for 24 weeks led to significant improvement in the magnitude of glycemic control. In the entire cohort, the mean reduction in $\mathrm{HbA}_{1 \mathrm{c}}$ was $2.8 \%(p<0.001)$, while mean reductions in FPG and PPPG were $4.0 \mathrm{mmol} / \mathrm{L}(\mathrm{p}<0.001)$ and $6.6 \mathrm{mmol} / \mathrm{L} \quad(\mathrm{p}<0.001) \quad$ respectively. These 
parameters also showed reductions of similar extent in the insulin naive patients and prior insulin users. In the entire cohort $49.1 \%$ of the participants achieved target $\mathrm{HbA}_{1 \mathrm{c}}$ level of $<7 \%$ after 24 weeks of BIAsp 30 therapy. Notably, $51 \%$ of insulin naive and $44.9 \%$ of prior insulin users reached target $\mathrm{HbA}_{1 \mathrm{c}}$ level of $<7 \%$ following BIAsp 30 treatment (Table II).

Table II: Effectiveness of BIAsp 30 in controlling hyperglycaemia

\begin{tabular}{|c|c|c|c|c|}
\hline & & $\begin{array}{l}\text { Full cohort } \\
(\mathrm{n}=580)\end{array}$ & $\begin{array}{l}\text { Insulin naïve } \\
(\mathrm{n}=400)\end{array}$ & $\begin{array}{l}\text { Prior insulin } \\
(\mathrm{n}=180)\end{array}$ \\
\hline \multirow{4}{*}{$\mathrm{HbA}_{1 \mathrm{c}}(\%)$} & $\mathrm{N}$ & 495 & 338 & 157 \\
\hline & Baseline & $10.0(1.3)$ & $10.0(1.3)$ & $10.0(1.2)$ \\
\hline & 24 weeks & $7.1(1.1)$ & $7.1(1.1)$ & $7.3(1.1)$ \\
\hline & Change, $p$ & $-2.8(1.4)^{* * *}$ & $-2.9(1.4)^{* * *}$ & $-2.7(1.3)^{* *}$ \\
\hline Proportion with & Baseline & 1.6 & 1.3 & 2.2 \\
\hline $\mathrm{HbA}_{1 \mathrm{c}}<7 \%$ & 24 weeks & 49.1 & 51 & 44.9 \\
\hline \multirow{4}{*}{$\begin{array}{l}\text { Fasting plasma } \\
\text { glucose } \\
(\mathrm{mmol} / \mathrm{L})\end{array}$} & $\mathrm{N}$ & 535 & 372 & 163 \\
\hline & Baseline & $10.6(1.9)$ & $10.7(2.0)$ & 10.4 (1.6) \\
\hline & 24 weeks & $6.6(0.9)$ & $6.6(0.9)$ & $6.7(0.8)$ \\
\hline & Change, $\mathrm{p}$ & $-4.0(1.9)^{* *}$ & $-4.1(2.0)^{* *}$ & $-3.7(1.7)^{* *}$ \\
\hline Post prandial & $\mathrm{N}$ & 534 & 371 & 163 \\
\hline plasma & Baseline & $15.5(2.5)$ & $15.6(2.6)$ & $15.3(2.3)$ \\
\hline glucose & 24 weeks & $8.9(1.1)$ & $8.9(1.2)$ & $8.9(1.0)$ \\
\hline$(\mathrm{mmol} / \mathrm{L})$ & Change, $\mathrm{p}$ & $-6.6(2.6)^{* *}$ & $-6.7(2.6)^{* *}$ & $-6.4(2.4)^{* *}$ \\
\hline
\end{tabular}

Data expressed in Mean (Standard deviation) for all variables unless mentioned otherwise

$* p<0.05, * * p<0.001$ compared to baseline

During the study the dose of insulin in the insulin naive patients was reduced from $28.3 \pm 10.1$ (baseline) to $26.4 \pm 8.7 \mathrm{U} /$ day at 24 weeks. In prior insulin users pre-study insulin dose was 28.5 \pm 9.6 $\mathrm{U} /$ day, this changed to $34.2 \pm 11.4 \mathrm{U} /$ day at baseline and decreased to $32.0 \pm 9.9 \mathrm{U} /$ day at the end of study. Furthermore, the pattern of OGLD use in the patients also changed during 24 weeks of the study. Use of sulfonylurea (SU) increased from $47.7 \%$ at baseline to $70.9 \%$ at 24 weeks. However, the use of metformin decreased from $43.2 \%$ at baseline to $20.0 \%$ at the end of the study period. Thiazolidinediones (TZDs) use also decreased from $28.8 \%$ to $14.5 \%$ during the study.

Body weight and other metabolic parameters: Following treatment with BIAsp 30 for 24 weeks, there was no clinically significant change in body weight, in insulin naïve or prior insulin users groups (Table III). Total cholesterol level for the entire cohort remained unchanged from $4.9 \pm 0.5$ $\mathrm{mmol} / \mathrm{L}$ to $5.0 \pm 1.1 \mathrm{mmol} / \mathrm{L}$ after 24 weeks of therapy. There was a mean reduction of $5.7 \mathrm{~mm} \mathrm{Hg}$ in the SBP of the entire cohort from 129.1 \pm 11.8 $\mathrm{mm} \mathrm{Hg}$ at baseline to $123.5 \pm 6.6 \mathrm{~mm} \mathrm{Hg}$ at 24 weeks $(\mathrm{p}<0.001)$. The reduction in SBP was higher in prior insulin users compared to insulin naïve patients.

Hypoglycaemia: At baseline, overall 83 hypoglycaemic events (1.86 events/person year) were observed in $78(13.4 \%)$ individuals of the entire cohort. After 24 weeks of therapy, significant reduction in the rate of overall hypoglycaemia was seen in the entire cohort, with $1(0.02$ events/person year) events occurring in $1(0.2 \%)$ patient $(\mathrm{p}<0.0001)$. A remarkable reduction in overall hypoglycaemic events was observed in the prior insulin users from 4.69 events/person year at baseline to 0.000 events/person year at 24 weeks $(\mathrm{p}<0.0001)$. In insulin naïve patients hypoglycaemic events decreased from 0.59 events/person year to 0.03 events/person year $(\mathrm{p}<0.05)$ [Table III].

Minor hypoglycaemic events in the entire cohort decreased significantly from 1.52 events/person year to 0.02 events/person year $(p<0.0001)$ following treatment with BIAsp 30. Nocturnal hypoglycaemia was also reduced following treatment with BIAsp 30 and was prominent in prior insulin users where it fell from 2.53 events/person year to 0.000 events/ person year $(\mathrm{p}<0.0001)$ [Table III].

Table III: Effect of BIAsp 30 on hypoglycaemia and body weight

\begin{tabular}{|c|c|c|c|c|}
\hline $\begin{array}{l}\text { Percent with } \\
\text { event/event per } \\
\text { person-year }\end{array}$ & & $\begin{array}{l}\text { Entire } \\
\text { cohort }\end{array}$ & $\begin{array}{l}\text { Insulin } \\
\text { naïve }\end{array}$ & $\begin{array}{l}\text { Prior } \\
\text { insulin }\end{array}$ \\
\hline \multirow{3}{*}{$\begin{array}{l}\text { Overall } \\
\text { Hypoglycaemia }\end{array}$} & Baseline & $13.4 / 1.86$ & $4.3 / 0.59$ & $33.9 / 4.69$ \\
\hline & 24 wks & $0.2 / 0.02$ & $0.3 / 0.03$ & $0.00 / 0.000$ \\
\hline & Change & $-13.2 * * *$ & $-0.4 * * *$ & $-33.9 * * *$ \\
\hline \multirow{3}{*}{$\begin{array}{l}\text { Minor } \\
\text { Hypoglycaemia }\end{array}$} & Baseline & $28.6 / 1.52$ & $3.3 / 0.52$ & $28.6 / 3.76$ \\
\hline & $24 \mathrm{wks}$ & $1.1 / 0.02$ & $0.4 / 0.03$ & $1.1 / 0.000$ \\
\hline & Change & $-27.5^{* * *} *$ & $-2.9 *$ & $-27.5^{* * *}$ \\
\hline \multirow{3}{*}{$\begin{array}{l}\text { Major } \\
\text { Hypoglycaemia }\end{array}$} & Baseline & $2.6 / 0.34$ & $0.5 / 0.07$ & $7.2 / 0.94$ \\
\hline & 24 wks & $0.00 / 0.000$ & $0.00 / 0.00$ & $0.00 / 0.000$ \\
\hline & Change & $-2.6 * * *$ & -0.5 & $-7.2 * *$ \\
\hline \multirow{3}{*}{$\begin{array}{l}\text { Nocturnal } \\
\text { Hypoglycaemia }\end{array}$} & Baseline & $6.5 / 0.90$ & $1.8 / 0.59$ & $29.6 / 2.53$ \\
\hline & $24 \mathrm{wks}$ & $0.3 / 0.02$ & $0.4 / 0.03$ & $0.00 / 0.000$ \\
\hline & Change & $-6.2 * * *$ & -1.4 & $-29.6^{* * * *}$ \\
\hline \multirow{4}{*}{ Body weight (kg) } & $\mathrm{N}$ & 532 & 367 & 165 \\
\hline & Baseline & $65.7(9.8)$ & $64.6(9.3)$ & $68.0(10.6)$ \\
\hline & $24 \mathrm{wks}$ & $65.6(9.7)$ & $64.6(9.2)$ & $67.8(10.4)$ \\
\hline & Change & $-0.1(1.4)$ & $0.0(1.4)$ & $0.3(1.3)^{*}$ \\
\hline
\end{tabular}

$\hat{a}$ - Patients experiencing at least one episode of hypoglycaemia $* p<0.05, * * p<0.001, * * * p<0.0001$ compared to baseline

Quality of Life: Improvement was noted in the quality of life measures of the participants following BIAsp 30 therapy. Across all the summary dimensions of HRQoL, significant improvements were observed following BIAsp 30 therapy. In the EQ-5D score, prior insulin users had an improvement of 0.226 points while insulin naïve patients reported a change of 0.159 points.

\section{Discussion}

The present study evaluated the safety and efficacy of BIAsp 30 in $\mathrm{A}_{1}$ chieve study participants from Bangladesh. After 24 weeks of treatment, $\mathrm{HbA}_{1 \mathrm{c}}$ reduction was $2.8 \%$ in the entire cohort, $2.9 \%$ in insulin naïve patients and $2.7 \%$ in prior insulin 
users group. This reduction was better than or similar to previously published reports of BIAsp 30. In the EuroMix trial, a $1.6 \%$ reduction in $\mathrm{HbA}_{1 \mathrm{c}}$ was reported when BIAsp 30 was used in combination with metformin for 26 weeks as an initiation regimen ${ }^{13}$. The IMPROVE study, one of the largest observational study, showed an overall change of $-2.3 \%$ in $\mathrm{HbA}_{1 \mathrm{c}}$ at end-of-study with BIAsp 30 therapy. The largest reduction was observed in the 'no pharmaceutical therapy' subgroup $(-3.1 \%)$, followed by OGLDs only ($2.1 \%)$ and insulin \pm OGLDs $(-2.0 \%)^{\mathbf{1 4}}$. Similar trend was also observed in the PRESENT study, where the mean reduction in $\mathrm{HbA}_{1 \mathrm{c}}$ was $1.8 \%$ after 6 months of treatment with BIAsp 30 in the overall cohort; $2.2 \%$ in insulin naïve patients and $1.60 \%$ in prior insulin users ${ }^{\mathbf{1 5}}$.

In this study, $49.1 \%$ of the study population achieved $\mathrm{HbA}_{1 \mathrm{c}}<7 \%$ after 24 weeks of BIAsp 30 therapy as compared to $1.6 \%$ population who had $\mathrm{HbA}_{1 \mathrm{c}}<7 \%$ during the baseline. These results, correspond to that of 1-2-3 study wherein approximately $40 \%$ of patients achieved target $\mathrm{HbA}_{1 \mathrm{c}}$ of $<7.0 \%$ in subgroup switching from basal insulin (NPH or glargine) to BIAsp $30^{\mathbf{1 6}}$. Also comparable results were observed in a 26 -week trial by Bebakar et al $(n=191)$, where $46 \%$ of the patients achieved $\mathrm{HbA}_{1 \mathrm{c}}$ of $<7 \%$ after BIAsp30 was added to the existing OGLD tretament ${ }^{17}$. Results from the INITIATE study showed that $65 \%$ patients in the premix insulin plus OGLD group achieved glycaemic targets while $40 \%$ patients achieved glycaemic target in the basal insulin plus OGLD group ${ }^{\mathbf{1 8}}$ thereby suggesting the improved efficacy of BIAsp 30.

The current study population shows significant reductions in both FPG and PPPG. These reductions were even greater than the reductions observed for entire BIAsp 30 cohort of $A_{1}$ chieve study $^{\mathbf{1 2}}$. The reduction in PPPG and FPG values was found to be higher in the insulin naïve group as compared to prior insulin users and the trend was similar to that of PRESENT study. The results from the Chinese cohort of IMPROVE study showed improvements of FPG ranging from 1.93 to 3.86 $\mathrm{mmol} / \mathrm{L}$ and PPPG ranging from 3.47 to 6.13 $\mathrm{mmol} / \mathrm{L}$ across the subgroups after 3-months of therapy ${ }^{19}$.

Hypoglycaemia is a deterrent factor to insulin therapy and has a major safety concern. However, factors that may increase the risk of hypoglycaemia, such as missed meals, dose administration errors and unawareness regarding hypoglycaemia were not taken into account while assessing hypoglycaemia. Because of advantage of meal time administration, premixed insulin analogues have the potential to reduce hypoglycaemic episodes, particularly in patients who do not follow the recommendations to administer human insulin 70/30 at least 30 minutes before a meal.

Previous literatures have reported few major hypoglycaemic episodes with BIAsp 30 treatment. Similarly results from the current study showed significant reductions in major, minor and nocturnal hypoglycaemia. In the PRESENT study, patients previously treated with insulin (with or without OGLD combination therapy) reported significantly lower minor hypoglycaemia 6 months after switching to BIAsp 30 in routine care (from approximately 9.0 to 2.3 events per patientyear). Also, similar results were reported in the IMPROVE study.

Apart from hyperglycaemia, other cardiovascular risk factors such as overweight/obesity and elevated blood pressure are important predictors of mortality in diabetic patients. Weight gain is also a potential side effect of treatment for patients with T2DM receiving certain oral therapies or insulin. Increase in body weight associated with antidiabetes therapy may diminish the clinical benefit of improved glycaemic control associated with such therapy. Patients in the IMPROVE and PRESENT studies showed no increase in body weight after 6 months therapy with BIAsp $30^{\mathbf{1 4}}$. This study also shows minimal change in weight $(0.1 \mathrm{kgs})$. Moreover, a favourable and clinically significant reduction in SBP was also noted in the Bangladesh BIAsp 30 cohort.

Although this study has provided an important insight about T2DM population status, safety and efficacy of BIAsp 30 in a Bangladeshi cohort, certain limitations of the study including its nonrandomized, observational nature, and possibility of recall bias should also be acknowledged.

Conclusion: The present Bangladesh subset analysis of the $A_{1}$ chieve study suggests that use of BIAsp 30 in insulin naïve and prior insulin therapy patients, improve glycaemic control without incurring hypoglycaemia or weight gain. Therefore, BIAsp 30 can be considered as a safe and effective option for initiating as well as intensifying insulin therapy for T2DM in Bangladesh.

\section{Acknowledgement}

We are thankful to Novo Nordisk for the financial support to conduct this study. We are also thankful to WorkSure for providing medical writing assistance. 


\section{References}

1. Wild S, Roglic G, Green A, Sicree R, King H. Global prevalence of diabetes: estimates for the year 2000 and projections for 2030. Diabetes Care. 2004; 27(5): 1047-53.

2. Shaw JE, Sicree RA and Zimmet PZ. Global estimates of the prevalence of diabetes for 2010 and 2030. Diabetes Res Clin Pract. 2010; 87(1): 4-14.

3. IDF Clinical Guidelines Task Force Brussels: International Diabetes Federation, 2005.

4. Garber AJ. Premixed insulin analogues for the treatment of diabetes mellitus. Drugs. 2006; 66(1): 31-49.

5. Glucose tolerance and mortality: comparison of WHO and American Diabetes Association diagnostic criteria. The DECODE study group. European Diabetes Epidemiology Group. Diabetes Epidemiology: Collaborative analysis Of Diagnostic criteria in Europe. Lancet. 1999; 354(9179): 617-21.

6. Hanefeld M, Fischer S, Julius U, Schulze J, Schwanebeck U, Schmechel H, Ziegelasch HJ, Lindner J. Risk factors for myocardial infarction and death in newly detected NIDDM: the Diabetes Intervention Study, 11-year follow-up. Diabetologia. 1996; 39(12): 1577-83.

7. Monnier L, Colette C, Rabasa-Lhoret R, Lapinski H, Caubel C, Avignon A, Boniface H. Morning hyperglycemic excursions: a constant failure in the metabolic control of non-insulin-using patients with type 2 diabetes. Diabetes Care. 2002; 25(4): 737-41.

8. Valensi P. Biphasic insulin aspart 30/70 (BIAsp 30) in the treatment of type 1 and type 2 diabetes. Diabetes Metab Syndr Obes. 2009; 2: 61-71.

9. Rolla AR. Insulin analog mixes in the management of type 2 diabetes mellitus. Pract Diabetol. 2002; 21: $36-43$.

10. Inzucchi SE, Bergenstal RM, Buse JB, Diamant $\mathrm{M}$, Ferrannini E, Nauck M, Peters AL, Tsapas A, Wender $\mathrm{R}$, Matthews DR. Management of hyperglycaemia in type 2 diabetes: a patient-centered approach. Position statement of the American Diabetes Association (ADA) and the European Association for the Study of Diabetes (EASD). Diabetologia. 2012; 55(6): 1577-96.

11. Home P, Naggar NE, Khamseh M, Gonzalez-Galvez G, Shen C, Chakkarwar P, Wenying Y. An observational non-interventional study of people with diabetes beginning or changed to insulin analogue therapy in non-Western countries: the $\mathrm{A}_{1}$ chieve study. Diabetes Res Clin Pract. 2011; 94(3): 352-63.
12. Kann P, Wascher T, Zackova V, Moeller J, Medding J, Szocs A, Mokan M, Mrevlje F, Regulski M. Starting insulin therapy in type 2 diabetes: twice-daily biphasic insulin aspart 30 plus metfor-min versus once-daily insulin glargine plus glimepiride. Exp Clin Endocrinol Diabetes. 2006; 114(9): 527-32.

13. Valensi P, Benroubi M, Borzi V, Gumprecht J, Kawamori R, Shaban J, Shah S, Shestakova M, Wenying Y; IMPROVE Study Group Expert Panel. Initiating insulin therapy with, or switching existing insulin therapy to, biphasic insulin aspart 3070 (NovoMix 30) in routine care: safety and effectiveness in patients with type 2 diabetes in the IMPROVE observational study. Int J Clin Pract. 2009; 63(3): 522-531.

14. Sharma SK, Al-Mustafa M, Oh SJ, Azar ST, Shestakova M, Guler S, Vaz JA. Biphasic insulin aspart 30 treatment in patients with type 2 diabetes poorly controlled on prior diabetes treatment: results from the PRESENT study. Curr Med Res Opin. 2008; 24(3): $645-52$.

15. Garber AJ, Wahlen J, Wahl T, Bressler P, Braceras $\mathrm{R}$, Allen E, Jain R. Attainment of glycemic goals in type 2 diabetes with once-, twice-, or thrice-daily dosing with biphasic insulin aspart 70/30 (The 1-2-3 study). Diabetes Obes Metab. 2006; 8(1): 58-66.

16. Bebakar WM, Chow CC, Kadir KA, Suwanwalaikorn S, Vaz JA, Bech OM; BIAsp-3021 study group. Adding biphasic insulin aspart 30 once or twice daily is more efficacious than optimizing oral antidiabetic treatment in patients with type 2 diabetes. Diabetes Obes Metab. 2007; 9(5): 724-32.

17. Bangladesh Endocrine Society, Diabetic Association of Bangladesh, Core Committee. Bangladesh insulin guideline (premix) for type 2 diabetes. Mymensingh Med J. 2011; 20(1): 173-82.

18. Gao Y, Guo XH. Switching from human insulin to biphasic insulin aspart 30 treatment gets more patients with type 2 diabetes to reach target glycosylated hemoglobin $<7 \%$ : the results from the China cohort of the PRESENT study. Chin Med J (Engl). 2010; 123(9): 1107-111.

19. Khutsoane D, Sharma SK, Almustafa M, Jang HC, Azar ST, Danciulescu R, Shestakova M, Ayad NM, Guler S, Bech OM; PRESENT Study Group. Biphasic insulin aspart 30 treatment improves glycaemic control in patients with type 2 diabetes in a clinical practice setting: experience from the PRESENT study. Diabetes Obes Metab. 2008; 10(3): 212-22. 